\title{
ADSORPTION OF DISSOLVED SUBSTANCES
}

\section{BY PERCY N. EVANS}

The term "adsorption" is here used to mean that action of solids on solutions by which the concentrations of the solutions are altered in immediate proximity to the solid surfaces. Whether the result is due to an attraction between the solid and the solute or is a surface phenomenon of the solution, is uncertain. A review of the principal work already done in this field of inquiry has recently appeared in this journal with a report of original investigations by Lyman J. Briggs. ${ }^{1}$

A number of experiments have been made at various times by the writer, with the assistance of students, and the results have not yet been published except in outline; ${ }^{2}$ though the investigation is incomplete it seems best to present without further delay the results so far obtained.

A preliminary series of experiments was carried out, with the assistance of Mr. Donald Davidson, toascertain how general the adsorption of dissolved substances by solids might be, and the magnitude of the effects. At that time the importance of some factors, such as the relative quantities of adsorber and solution, was not realized and the data were not recorded, so that the experiments cannot be discussed on the same basis as later ones; the following summary will here suffice:

Twentieth-equivalent-normal tartaric acid showed a loss of nearly $\mathrm{I} 2$ percent in acidity of the supernatant solution with filter paper; twentieth-normal potassium hydroxide about the same in alkalinity with filter paper; 2.6 percent sucrose solution with animal charcoal was reduced to 1.9 percent, by polarimetric measurement; fiftieth-normal acetic acid with ignited precipitated silica gave a loss in acidity of over 5 percent; fiftieth-normal hydrochloric acid with cotton

\footnotetext{
${ }^{1}$ Jour. Phys. Chem., 9, 617 (1905).
}

2 Proc. Indiana Acad. Sci., Igor. 
cloth showed 4 percent loss in acidity; fiftieth-normal hydrochloric acid with ignited silica gave 2.5 percent loss in acidity; fiftieth-normal ammonia with cotton cloth gave about i 5 percent loss in alkalinity. All of these experiments showed, then, a positive adsorption of from 2.5 to 27 percent of the dissolved substance.

Several other experiments showed no effect whatever; 2.5 percent sucrose with sugar-charcoal, with lamp-black, with sand; tartaric acid (concentration not recorded) with cotton cloth; tenth-normal sodium thiosulphate solution (reduction equivalent) with ignited precipitated silica.

Some experiments with sodium chloride solutions and filter paper seemed to indicate negative adsorption-a gain in the strength of the supernatant solution-but this result was afterwards found to be due to chlorides in the paper, none of the laboratory supply being entirely free.

The conclusion from this series of experiments is that while adsorption is very pronounced in some cases, it is not shown by all solids with all solutions.

A second series of experiments, made with the assistance of Miss Mary E. Brown, was a more systematic investigation of the behavior of filter paper towards solutions of hydrochloric acid of various strengths.

The procedure followed in each experiment was to place IOO $\mathrm{cc}$ of the hydrochloric acid solution in a bottle, add 5 grams of air-dried filter paper cut into small pieces, a piece at a time to insure uniform contact with the solution, stopper the bottle, agitate thoroughly but not violently enough to disintegrate the paper, and finally to titrate $\mathrm{Io} \mathrm{cc}$ of the supernatant solution and of the original solution not treated with paper, respectively, with a sodium hydroxide solution of somewhat less than equivalent strength, using phenolphthalein as indicator. Several titrations of each kind were made in every case.

Regarding the time of standing of the solution in contact with the paper, it was found experimentally that the amount 
of adsorption in a particular case was identical after various periods ranging from five minutes to a week. It may be remarked that this would seem to exclude the possibility of the change in concentration being due to chemical action. The results obtained were as follows:

Hydrochloric Acid Solutions and Fititer Paper

\begin{tabular}{c|r|c|c}
\hline $\begin{array}{c}\text { Gram-equiv. } \\
\text { per liter }\end{array}$ & $\begin{array}{c}\text { Liters per } \\
\text { gram-equiv. }\end{array}$ & $\begin{array}{c}\text { Percent of } \\
\text { solute re- } \\
\text { moved }\end{array}$ & $\begin{array}{c}\text { Milligrams of } \\
\text { solute removed } \\
\text { per gram of } \\
\text { adsorber }\end{array}$ \\
\hline I.030 & 0.97 & doubtful & doubtful \\
0.357 & 2.80 & doubtful & doubtful \\
0.278 & 3.60 & 0.66 & 1.64 \\
0.166 & 6.03 & I.09 & I.32 \\
0.082 & 12.06 & 1.28 & 0.78 \\
0.062 & 16.20 & 1.88 & 0.66 \\
0.043 & 23.50 & 2.52 & 0.68 \\
0.031 & 32.70 & 3.07 & 0.56 \\
0.030 & 32.80 & 3.18 & 0.58 \\
0.023 & 43.88 & 4.61 & 0.64 \\
0.021 & 48.20 & 4.85 & 0.74 \\
0.017 & 58.24 & 5.98 & 0.60 \\
0.014 & 72.70 & 8.81 & 0.72 \\
0.010 & 96.40 & 8.12 & 0.62 \\
0.008 & $I 16.38$ & 13.98 & 0.72 \\
0.007 & 144.80 & 14.72 & 0.62 \\
& & & \\
& & &
\end{tabular}

The figures found for the percent of acid removed form a fairly regular series, increasing with the dilution, but for the highest two concentrations the effect was so slight as to make it doubtful whether any adsorption took place, there being no difference in the solutions treated and those not treated with paper according to most of the titrations.

The absolute weight adsorbed is nearly uniform through a wide range of concentration; that these figures do not form a regular series is to be expected from the experimental nature of the work-the calculation of small differences between comparatively large measured quantities. This is particularly true at the beginning of the series, where the differences 
are almost inappreciable, and at the end of the series; where the accuracy of the titrations is less, owing to the difficulty of noting the end-point with highly dilute solutions.

A third series of experiments was made with the assistance of Mr. Edward Mueller.

The first solute chosen was sodium chloride. The procedure was, as before, to place 5 grams of air-dried filter paper in contact with roo $\mathrm{cc}$ of the solution, and to determine the difference in concentrations of the supernatant solution treated and that not treated with paper. In this series chlorine was determined. volumetrically with standard silver nitrate, using potassium chromate as indicator, the silver nitrate solution being approximately equivalent in strength to the test solutions in each case. The filter paper was found to contain chlorides, but uniformly distributed, and instead of washing out the chlorine as in earlier work, allowance was made for its presence.

The results obtained were as follows:

Sodium Chloride Solutions and Filter Paper

\begin{tabular}{c|c|c|c}
$\begin{array}{c}\text { Gram-equiv. } \\
\text { per liter }\end{array}$ & $\begin{array}{c}\text { Liters per } \\
\text { gram-equiv. }\end{array}$ & $\begin{array}{c}\text { Percent of } \\
\text { solute re- } \\
\text { moved }\end{array}$ & $\begin{array}{c}\text { Milligrams of } \\
\text { solute removed } \\
\text { per gram of } \\
\text { adsorber }\end{array}$ \\
\hline 0.02 & 50 & 0.00 & 0.00 \\
0.01 & IOO & 1.36 & 0.16 \\
0.005 & 200 & 2.45 & 0.14 \\
\hline
\end{tabular}

A series of experiments made in just the same way with potassium chloride solutions gave the following results:

Potassium Chloride Solutions and Filter Paper

\begin{tabular}{c|c|c|c}
\hline $\begin{array}{c}\text { Gram-equiv. } \\
\text { per liter }\end{array}$ & $\begin{array}{c}\text { Liters per } \\
\text { gram-equiv. }\end{array}$ & $\begin{array}{c}\text { Percent of } \\
\text { solute re- } \\
\text { moved }\end{array}$ & $\begin{array}{c}\text { Milligrams of } \\
\text { solute removed } \\
\text { per gram of } \\
\text { adsorber }\end{array}$ \\
\hline 0.100 & IO & doubtful & doubtful \\
0.067 & I5 & 0.27 & 0.27 \\
0.050 & 20 & $0.8 \mathrm{I}$ & 0.60 \\
0.033 & 30 & I.I8 & 0.58 \\
0.013 & 75 & 2.00 & 0.39 \\
0.007 & I5O & 2.55 & 0.25 \\
0.005 & 200 & 2.75 & 0.20
\end{tabular}


Two experiments with barium chloride solutions, carried out in the same way except that chlorine was determined gravimetrically as silver chloride, gave the following results:

Barium Chloride Solutions and Filter Paper

\begin{tabular}{c|c|c|c}
$\begin{array}{c}\text { Gram-equiv. } \\
\text { per liter }\end{array}$ & $\begin{array}{c}\text { Liters per } \\
\text { gram-equiv }\end{array}$ & $\begin{array}{c}\text { Percent of } \\
\text { solute re- } \\
\text { moved }\end{array}$ & $\begin{array}{c}\text { Milligrams of } \\
\text { solute removed } \\
\text { per gram of } \\
\text { adsorption }\end{array}$ \\
\hline 0.020 & 50 & 0.00 & 0.00 \\
0.005 & 200 & 0.00 & 0.00
\end{tabular}

The concentrations are here expressed in terms of equivalent-normal.

A series of experiments with hydrochloric acid solutions and filter paper carried out in the usual way gave the following results, the determinations being made volumetrically with standard sodium hydroxide solution and phenolphthalein as indicator:

Hydrochloric Acid Solutions and Filter Paper (SECOND SERIES)

\begin{tabular}{c|c|c|c}
\hline $\begin{array}{c}\text { Gram-equiv. } \\
\text { per liter }\end{array}$ & $\begin{array}{c}\text { Liters per } \\
\text { gram-equiv. }\end{array}$ & $\begin{array}{c}\text { Percent of } \\
\text { solute re- } \\
\text { moved }\end{array}$ & $\begin{array}{c}\text { Milligrams of } \\
\text { solute removed } \\
\text { per gram of } \\
\text { adsorber }\end{array}$ \\
\hline 0.50 & 2 & 0.00 & 0.00 \\
0.25 & 4 & 0.57 & 1.04 \\
0.20 & 5 & 1.48 & 2.15 \\
0.10 & IO & 2.49 & 1.81 \\
0.04 & 25 & 4.96 & 1.44 \\
0.02 & 50 & 9.46 & 1.38 \\
0.01 & IOO & 3.03 & 0.95 \\
0.004 & 250 & 23.64 & 0.69
\end{tabular}

Comparing this series of experiments and the earlier one with hydrochloric acid and filter paper, it will be noticed that the adsorption percent for corresponding concentrations is larger in every case in the later series, also for the absolute weight of solute adsorbed. This is probably due to a different grade of filter paper having been employed, as the experiments were performed a year later, and a difference in the average coarseness of the fibre would involve a corresponding difference in the adsorption produced, due to greater or less surface in the same weight.

These experiments with solutions of sodium chloride, 
potassium chloride, barium chloride, and hydrochloric acid, with filter paper, all show the following: at highest concentrations there is no adsorption; at lower concentrations the percent of solute adsorbed increases with the dilution, except in the case of barium chloride solutions, which showed no adsorption even at the highest dilution; the absolute weight of solute adsorbed is zero at high concentrations, and increases and then decreases with increasing dilution, except barium chloride solutions, which showed no adsorption.

A fourth series of experiments was made, with the assistance of Miss Frances M. DeFrees, on the adsorption of copper sulphate and of potassium chloride from their solutions by filter paper.

In each experiment Ioo cc of the solution stood in contact with 5 grams of filter paper, as in the preceding experiments. Copper was determined volumetrically with an approximately equivalent solution of potassium cyanide. Here, again, experiment showed the result to be independent of the time of standing, up to forty-eight hours. The following results were obtained:

COPper Sulphate Solutions ANd Filter PAPER

\begin{tabular}{|c|c|c|c|}
\hline $\begin{array}{l}\text { Grami-equiv. } \\
\text { per liter }\end{array}$ & $\begin{array}{c}\text { Liters per } \\
\text { gram-equiv. }\end{array}$ & $\begin{array}{l}\text { Percent of } \\
\text { solute re- } \\
\text { moved }\end{array}$ & $\begin{array}{l}\text { Milligrams of } \\
\text { solute removed } \\
\text { per gram of } \\
\text { adsorber }\end{array}$ \\
\hline 1.00 & 1.0 & 0.00 & 0.00 \\
\hline 0.50 & 2.0 & 0.00 & 0.00 \\
\hline 0.33 & 3.0 & 0.00 & 0.00 \\
\hline 0.25 & 4.0 & 0.00 & 0.00 \\
\hline 0.20 & 5.0 & 0.27 & 0.87 \\
\hline O.I7 & 6.0 & 0.85 & 2.26 \\
\hline 0.14 & 7.0 & I. 48 & 3.39 \\
\hline O. IO & I 0.0 & 2.42 & 3.88 \\
\hline 0.08 & 12.5 & 3.18 & 4.07 \\
\hline 0.07 & 15.0 & 3.94 & 4.00 \\
\hline 0.05 & 20.0 & 4.70 & 3.77 \\
\hline 0.04 & $25: 0$ & 5.57 & 3.57 \\
\hline 0.03 & 35.0 & $7 \cdot 32$ & 3.39 \\
\hline 0.02 & 50.0 & $9 . \mathrm{II}$ & $2.9 \mathrm{I}$ \\
\hline 0.013 & 75.0 & I 0.42 & 2.22 \\
\hline 0.010 & 100.0 & 12.33 & 1.97 \\
\hline 0.008 & I 25.0 & I 5.35 & 1.96 \\
\hline 0.004 & 250.0 & 25.77 & I. 64 \\
\hline
\end{tabular}


Another set of experiments was made with copper sulphate solutions and filter paper, in which the sulphuric acid instead of the copper was determined; this was done volumetrically with standard barium chloride solution, the endpoint being reached when no further precipitation resulted on addition of the reagent after allowing the precipitate to settle. The following figures were obtained:

Copper Sulphate Solutions and Filter Paper (SECOND SERIES)

\begin{tabular}{c|c|c|c}
\hline $\begin{array}{c}\text { Gram-equiv. } \\
\text { per liter }\end{array}$ & $\begin{array}{c}\text { Liters per } \\
\text { gram-equiv. }\end{array}$ & $\begin{array}{c}\text { Percent of } \\
\text { solute re- } \\
\text { moved }\end{array}$ & $\begin{array}{c}\text { Milligrams of } \\
\text { solute removed } \\
\text { per gram of } \\
\text { adsorber }\end{array}$ \\
\hline 9.50 & 2 & 0.00 & 0.00 \\
0.2 & 5 & 0.65 & 2.72 \\
0.10 & 10 & 2.91 & 4.66 \\
0.05 & 20 & 4.64 & $3.7 \mathrm{I}$
\end{tabular}

A comparison of these two sets of experiments with copper sulphate shows as close an agreement as was to be expected in view of the experimental difficulties; the "percent of solute removed" being for half-normal o.oo in both series, fifthnormal 0.27 and 0.85 , for tenth-normal 2.42 and $2.9 \mathrm{I}$, and for twentieth-normal 4.70 and 4.64 , respectively.

A series of experiments with potassium chloride solutions and filter paper, in which chlorine was determined by titration with standard silver nitrate solutions volumetrically, gave the following results :

Potassium Chloride Solutions and Filter Paper

(SECOND SERIES)

\begin{tabular}{c|c|c|c}
$\begin{array}{c}\text { Gram-equiv. } \\
\text { per liter }\end{array}$ & $\begin{array}{c}\text { Liters per } \\
\text { gram-equiv. }\end{array}$ & $\begin{array}{c}\text { Percent of } \\
\text { solute re- } \\
\text { moved }\end{array}$ & $\begin{array}{c}\text { Milligrams of } \\
\text { solute removed } \\
\text { per gram of } \\
\text { adsorber }\end{array}$ \\
\hline 0.100 & IO & 0.00 & 0.00 \\
0.050 & 20 & 0.58 & 0.44 \\
0.029 & 35 & 0.69 & 0.30 \\
0.020 & 50 & 1.02 & 0.31 \\
0.010 & 100 & 2.64 & 0.40 \\
0.004 & 250 & 3.91 & 0.23 \\
0.002 & 500 & 5.34 & 0.16
\end{tabular}


A comparison of these figures with the earlier series for potassium chloride and filter paper shows a fair agreement throughout.

These experiments with copper sulphate solutions and potassium chloride solutions, show the same points of interest as the earlier ones, namely, at highest concentrations there is no adsorption, at lower concentrations the percent of solute adsorbed increases with the dilution, and the weight of solute adsorbed is zero at high concentrations, increasing and then decreasing with increasing dilution.

A fifth series of experiments was made, with the assistance of Miss Margaret F. Haywood, to compare the behavior of silica with that of filter paper towards solutions of copper sulphate.

The silica was prepared from sodium silicate solution (water glass); hydrochloric acid was added, the material evaporated to dryness, moistened with hydrochloric acid and evaporated to dryness three times, powdered, washed free from chloride, passed through a hundred-mesh sieve, and kept well mixed for use. In each experiment Ioo cc of the copper sulphate solution was placed in a bottle with ro grams of the silica, shaken well, and allowed to settle. The copper sulphate solution, both that treated with silica and the untreated, was titrated with an approximately equivalent potassium cyanide solution in presence of ammonia.

The results obtained were as follows, the concentrations being expressed in terms of equivalent normal strength: 
COPPER SUlphate SOLUTIONS AND SILICA

\begin{tabular}{c|c|c|c}
\hline $\begin{array}{c}\text { Gram-equiv. } \\
\text { per liter }\end{array}$ & $\begin{array}{c}\text { Liters per } \\
\text { gram-equiv. }\end{array}$ & $\begin{array}{c}\text { Percent of } \\
\text { solute re- } \\
\text { moved }\end{array}$ & $\begin{array}{c}\text { Milligrams of } \\
\text { solute removed } \\
\text { per gram of } \\
\text { adsorber }\end{array}$ \\
\hline 1.000 & I & 0.00 & 0.00 \\
0.500 & 2 & 0.00 & 0.00 \\
0.250 & 4 & 0.00 & 0.00 \\
0.200 & 5 & doubtful & doubtful \\
0.100 & IO & 0.00 & 0.00 \\
0.050 & 20 & doubtful & doubtful \\
0.033 & 30 & 0.00 & 0.00 \\
0.025 & 40 & 0.86 & 0.17 \\
0.024 & 42 & 0.98 & 0.19 \\
0.022 & 45 & 2.48 & 0.44 \\
0.021 & 48 & 3.52 & 0.59 \\
0.020 & 50 & 4.13 & 0.68 \\
0.017 & 60 & 4.92 & 0.69 \\
0.013 & 75 & 5.06 & 0.53 \\
0.010 & IOO & 5.05 & 0.40
\end{tabular}

It will be observed that for corresponding concentrations the adsorption is much less marked with silica than with filter paper; this may be due to the difference in the chemical nature of the two materials or to smaller surface in the case of the silica. The results with silica show all the peculiarities already discussed earlier; the dilution at which adsorption first unmistakably appears is much higher with silica than with filter paper-fortieth-normal and fifth-normal. The dilution at which the maximum weight of solute is adsorbed is also much higher with silica than with filter paper-sixtiethnormal and twelfth-normal.

\section{Conclusions}

Some solutions show adsorption with filter paper, silica, and other solids, some solutions do not.

Some solutes show adsorption in dilute solution but not in concentrated solution.

No cases were found of negative adsorption.

The proportion of solute removed increases with the dilution.

The weight of solute removed by the adsorber shows with increasing dilution, first an increase then a decrease.

Chemical Laboratory of Purdue University,

Lafayette, Indiana, January, I906. 